\title{
Analysis of Energy Recovery System of Formula One Cars
}

\author{
$\underline{\text { Karan Bopaiah }}$ \\ Auburn University, Alabama, USA
}

\author{
Stephen Samuel \\ Oxford Brookes University, Oxford, United Kingdom
}

\begin{abstract}
This study analyzes the performance of the Energy Recovery System (ERS) of a Formula One car (F1) based on the qualification performance of 19 drivers for the first calendar race of the 2019 FIA Formula One World Championship ${ }^{\circledR}$. In this study, the race circuit analysed was split into different sectors to examine the energy transfer between the Motor Generator Unit-Kinetic (MGU-K) and the Energy Storage (ES) systems. Positive Kinetic Energy (PKE) concept was used for estimating the energy deployment potential of the ERS along with numerical simulations for estimating the energy recovering potential. This investigation highlights the strategies used by different drivers and the effect of driver to driver variation on their ERS performance during qualification. The methodology demonstrated in this study is able to identify the correlation between the unique driving style of individual drivers and the ERS strategies used by the teams for maximizing the performance of their car. The findings of this study illustrate that Power Unit (PU) manufacturers can take advantage in certain sectors, therefore, sector-wise optimization can be used by teams for optimising the ERS performance as this would in-turn maximize the car's performance.
\end{abstract}

\section{Introduction}

Internal Combustion Engines (ICE)'s has always been the sole source of propulsion of a Formula One (F1) car since its inception in 1950 until 2008. All along the way, Federation Internationale de l'Automobile (FIA), the governing body of F1 has put a strong emphasis on improving and enhancing the ICE's efficiency by restricting regulations for technological advancements and allowing teams to use their own state of the art methods to increase the powerper litre of the cars [1]. Over the past few years, a newer and more sought-after technology that is rapidly gaining interest in both the automotive and motorsport world is hybridization. The use of motors and generators coupled to a battery that can recover, store and use the otherwise wasted energy during propulsion like braking energy and heat energy from the exhaust to improve the overall efficiency of the car [2]. There is also an increased emphasis on making motor racing more relevant in terms of the efficiency with which fuel energy can be converted into useful work. With motorsports being the primary motivation for automotive engineering studies, research and advancements, it become pre-dominant for engineers in F1 to develop solutions that improve well-to-wheels (WTW) efficiency as a full vehicular system [2].

In 2006, the FIA introduced new regulations limiting the number of engines per Grand Prix, putting the emphasis on increased reliability.
It enabled the manufacturers to design and develop a fuel-efficient engine for optimum power delivery and increased reliability [3] [4]. The year 2009 [5] saw the introduction of Hybrid Powertrain system in F1 with the term Energy Recovery Systems (ERS) being coined. The ERS consists of a motor generator unit which recovers energy during braking, Control Electronics (CE) to transfer the energy and a battery to store and use this energy. This was termed as Kinetic Energy Recovery System (KERS). This technology was introduced with the sole source of making F1 cars gain a new road-relevant, energyefficient power source. The KERS provided the ICE an additional $400 \mathrm{~kJ}$ of energy which corresponds to $80 \mathrm{bhp}$ of extra power for 6.6 seconds per lap [6].

In 2014, the FIA introduced the switch from 2.4 litre V8 engines to 1.6 litre V6 turbo engines. Stringent regulations were introduced to limit the power from ICE, while allowing heat energy from the exhaust and brakes to be recovered, stored and deployed for additional power. The engine was no longer solely responsible for developing and supplying power to the wheel and hence the term power-Unit (PU) came into practice [7]. The new ERS is capable of providing an additional 160 bhp that dramatically increases the PU's overall efficiency [8]. The PU is deemed to consist of six separate elements: the ICE, the motor generator unit-kinetic (MGU-K), the motor generator unit-heat (MGU$\mathrm{H})$, the energy store (ES), turbocharger (TC) and control electronics (CE) [9]. With regulations dictating everything in Formula One, it is clear that the technological advancements in the engine and powertrain subsystem has been highly restrictive [10]. With this in mind, keen interest has been put into optimisation of ERS in order to maximize the PU output to achieve a competitive edge against other rival teams [11]. Further insights into the functioning of the ERS is described in our previous work [7]. Unlike, the regulations prior to 2014, the current engine's maximum power output is fixed by limiting the fuel flow rate to $100 \mathrm{~kg} / \mathrm{hr}$ above $10500 \mathrm{rpm}$ [12].

Managing the energy flow within the ERS to minimize energy losses, heat losses and resistance losses therefore pose the biggest challenges for optimisation. Since the sport is highly competitive and the minutest of gains in power and efficiency make a difference in race positions, optimization of ERS for maximising the car's performance has been the challenge faced by many teams [13]. Hence, this work analyses the ERS used by different teams in the first calendar race of the 2019 FIA Formula One World Championship ${ }^{\circledR}$ during qualification. Numerical Simulations were performed in GT-Suite on the 1.6L V6 ICE as well as the full vehicle model that was developed in our previous work [7] to examine the performance of ERS. A comparative analysis of the energy recovery and deployment potential of the ERS was carried out for 19 out of the 20 drivers driving in the 2019 F1 season. The 
estimation of Positive Kinetic Energy (PKE) from the vehicle speed trace to evaluate the energy recovery and deployment dynamics of each car was also carried out. Correlating PKE with comparative analysis of ERS provides an in-depth understanding of the car's performance over individual sectors of the track and the whole lap. The following sections outline the modelling methodology used, validation of the model with real world data and use of PKE to estimate the vehicle's performance. This is then followed by a description of the various types of analysis carried out and the interpretation of results from these analyses.

\section{Modelling Methodology}

\section{Engine Modelling}

The scope of this study is entirely dictated by the 2019 F1 Technical [10] and Sporting Regulations [12]. The powertrain of an F1 car consists of all the torque transmission systems like the ICE with all the ancillaries, the ERS and all the actuation sub-systems required to keep it operational all time excluding the drive shafts [10].

Since the maximum fuel flow rate is limited to $100 \mathrm{~kg} / \mathrm{hr}$, assuming a calorific value of $44,600 \mathrm{~kJ} / \mathrm{kg}$ [14] and a maximum brake thermal efficiency of $50 \%$ [15], the maximum power output of the ICE can be calculated and set as the target for the V6 engine that is modelled in GT-Power. The maximum power output from the ICE is estimated by:

$$
P=\dot{m}_{\text {fuel }} \times \eta_{\text {b-thermal }} \times Q_{H V}
$$

Detailed description of the V6 engine and full car modelling methodology can be found in [7]. The air fuel ratio $(\lambda)$ was chosen as 1 . Therefore, by finding the ratio between the mass flow rate of the theoretical naturally aspirated engine and the mass flow rate of air required to meet the restricted mass flow rate of fuel, the pressure ratio required by the compressor can be calculated:

$$
r_{\text {intake pressure }}=\frac{\dot{m}_{\text {air }}}{\dot{m}_{\text {air }, N A}}
$$

Henceforth, using the information for the intake pressure ratio as well as the mass flow rate of air required, the compressor can be sized. The turbocharger that best fitted the specification required is the BorgWarner EFR9180 [16]. The maps of the compressor and turbine have been extracted using image to data software [17] and used for the compressor and turbine maps respectively for the V6 engine simulation model on GT-Power. The sizing of the intake and exhaust valves are done based on bore to valve diameter ratio using 50 Historical F1 engine data [18]. Once the engine was assembled on GT-Power, a Proportional Integral Derivative (PID) controller was introduced, in order to regulate the turbine waste gate and therefore achieve the specified mass flow rate of fuel for each engine speed. The engine model with a PID controlled waste gate was run for the range of 4000RPM to 15000RPM with an increase of 500RPM per case for throttle positions ranging from 0 to $100 \%$ with $10 \%$ increments. Assuming that a $10 \%$ throttle decrease would result in a $10 \%$ area decrease for the air intake, and since the mass flow rate of air is directly related to the area, as well as the mass flow rate of fuel, a linear relationship between throttle position and mass flow rate of fuel can be established [7]. A 2D map could then be created (Engine RPM vs Throttle Position) for the power deployed and recovered by the MGU$\mathrm{H}$ which is directly linked to the turbocharger through a fixed gear ratio as it is specified in section 5.2.4 [10].

\section{Full Vehicle Modelling}

In the full vehicle model, for the MGU-K, a motor-generator template was created using the efficiency values obtained from the published literature [19] [20] [21]. The map was scaled to fit the rotational speed and torque of the MGU-K. The minimum and maximum torque values for the MGU-K were calculated for RPM ranging from -50000RPM to 50000RPM since this is the maximum allowed rotational speed of the MGU-K as specified in article 5.2.3 [10]. For the minimum torque values, $-120 \mathrm{~kW}$ was used while for maximum $120 \mathrm{~kW}$ was used as it is specified in section 5.2.2 [10]. The MGU-K was linked to the crankshaft of the engine with the means of a permanent and mechanical fixed speed gear ratio. The ratio chosen initially was 3.33 , taking into consideration the ratio between the maximum rotational speed of the MGU-K allowed over the maximum rotational speed of the ICE allowed. The battery size initially used in the full car model was decided from [22], where a parametric study carried out showed 140 cells in series of 20A-h to be used with a targeted State of Charge (SOC) of 0.8 , for best race performance. The target SOC for Qualification was set to 1 as maximum output from the ERS is essential for optimising the energy deployment and recovery.

Since the regulations limit the total energy that can be recovered and deployed from the ERS, efficiency gains in this aspect is subject to optimal management of energy flow. The conditions imposed by FIA which most notably influence ERS performance [10] are:

- The energy recovered/stored at any point of time must be deployed via the MGU-K to the wheels (Art.5.2.1 and Appendix 3 [10]).

- $\quad$ The total energy recoverable from the Energy Storage (ES) to the MGU-K is limited to $2 \mathrm{MJ}$ per lap respectively (Appendix 3 [10]). This limitation coupled with the regulation stating that the maximum weight of the Energy Storage System (ESS) should be more than $20 \mathrm{~kg}$ and less than $25 \mathrm{~kg}$ is imposed to limit overemphasis of teams on battery development, flywheels and supercapacitors (Art.5.4.3 [10]).

- The MGU_H on the other hand is allowed recover and deploy unlimited energy between the MGU-K and the MGU-H and the MGU-H and the Energy Storage making energy recovery from the turbocharger 'free' [23]. This helps to make sure that the cars do not experience any turbo-lag and power is instantaneously delivered to the engine (Art.5.2.4 and Appendix 3 [10]).

Appendix 3 in the FIA technical regulations [10] state that the difference between the maximum and minimum SOC of the ES may not exceed $4 \mathrm{MJ}$ at any time the car is on the track. This can be effectively translated that if the MGU-K is recovering energy and deploying it immediately rather than storing it for a long period of time, the SOC depletion in the battery is just $2 \mathrm{MJ}$ per lap if the MGU-K is able to recover and deploy all the energy as per regulations [10]. Since the maximum power deployed is limited to $120 \mathrm{~kW}$ from the MGU-K to the wheels, this accounts for an effective boost of a $160 \mathrm{hp}$ for 33.33 seconds. Taking the fastest lap-time around all the circuits [24] gives 
an average circuit time of 90 secs, meaning that the ERS can effectively provide a power boost to the driver for more than $33.33 \%$ of the lap time.

\section{Model Integrity and Derived Information}

The driver data to be fed to the full car model was extracted from Formula One TV App [25] for qualification in terms of engine speed, vehicle speed and gear number for the first calendar race of the 2019 FIA Formula One World Championship ${ }^{\circledR}$. This was done using Optical Character Recognition (OCR) from the vision toolbox in MATLAB [26] [27]. This was then compared against published lap times by FIA [28] to validate the accuracy of extracted data. The transmission ratio for each driver was derived and the gear shift speeds were extracted from the data and specifically fed to the full car model to realise driver to driver variation.

$$
\omega_{\text {engine }}=i_{o} i_{\theta} \frac{V_{\text {vehicle }}}{r_{\text {tyre }}}
$$

The coefficients for lift and drag as well as the frontal area were obtained by Computational Fluid Dynamics (CFD) simulations using the chassis designed by Perrinn [29] for the 2019 season. The circumference of a radial tyre will decrease by around $1 \%$ [30] when the tyre is loaded on the ground. Taking this into consideration, as well as the fact that circumference is directly related to wheel diameter, the corrected diameter for the tyre was calculated as $99 \%$ of total wheel diameter as specified in the regulations [10]. The above values were set constant to all the cars to solely analyse the cars based on their ERS capabilities and gain qualitative understanding of other factors such as effect of aerodynamics, vehicle dynamics and tire mechanics on performance [31] [32] [33] [34]. The driver data acquired was then fed into the model such as target speed to the driver template to replicate vehicle speed, gear ratio for the transmission and shift speeds for gear transmission.

Based on the target speed, gear number and the tractive torque required to propel the vehicle, the power required by the vehicle is calculated by the model. If the power demand by the driver is more than the maximum power output from the engine, the additional power required is delivered from the ERS. An energy storage controller is modelled in this case which determines the energy to be recovered or deployed. This controller follows the regulations that energy can be transferred from MGU-K to MGU-H, MGU-H to battery, MGU-K to battery and vice versa for all the cases [10]. Although the control logic incorporated in the ES controller is quite complex and needs to be robust, the primary emphasis here is given to understand the energy transfer from the battery to the MGU-K and vice-versa as the future of the sport relies on minimizing the complexity factors affecting the engine and increasing the overall efficiency of the car by maximizing MGU-K power recovery [35]. The modelling is done in such a way that under all circumstances, the ES controller follows all the regulations pertaining to ERS [10] to make sure that the car is legal to run at all times.

In order to get reliable data from the model and make sure that these results are an actual representative measure of an F1 car on track, the full car model is run with the data extracted from the Formula One TV App [25] as well as data derived from FIA [28] for 19 drivers for the first calendar race of the 2019 FIA Formula One World Championship ${ }^{\circledR}$. One of the main parameters to establish the accuracy of OCR (experimental) and the GT-Suite model (numerical) against actual lap times is the distance travelled by the car in that particular time. Since 1 lap around the circuit is a certain set distance which needs to be covered by all the drivers, the accuracy of the distance travelled that is calculated both experimentally and numerically can be compared against the actual length of the track. A comparative analysis of the error in distance travelled is illustrated in Figure 1. It can be seen that the maximum error is less than $2.2 \%$ for numerical and $1.8 \%$ for experimental. Average error is less than $0.6 \%$ across all the drivers both experimentally and numerically. The velocity and gear shift profiles are shown for 3 drivers in Figure 2 and Figure 3 for both the experimental and numerical data.

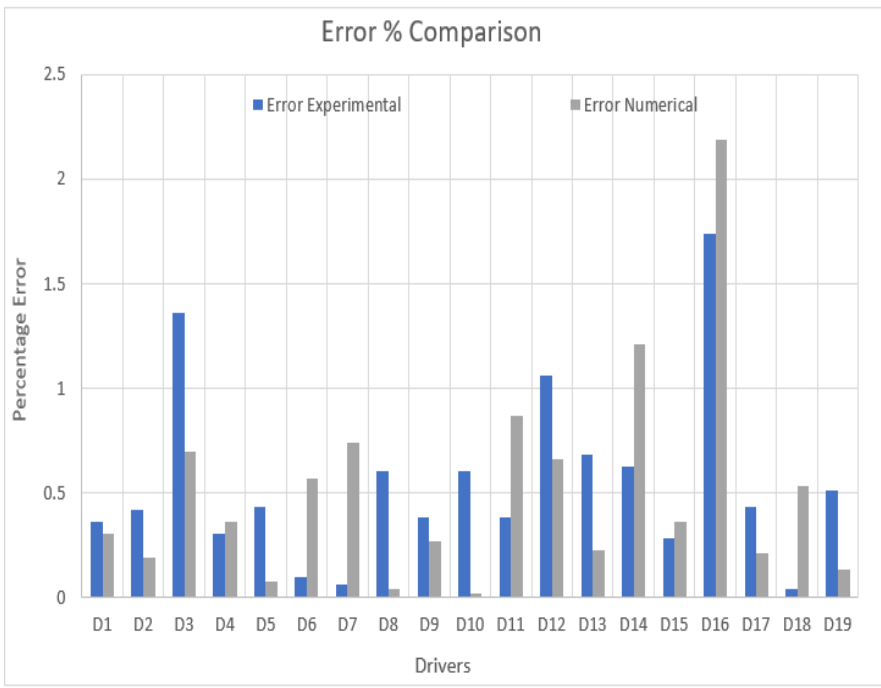

Figure 1. Error \% comparison for distance travelled (single lap) of drivers from numerical simulations and derived data from F1 TV App

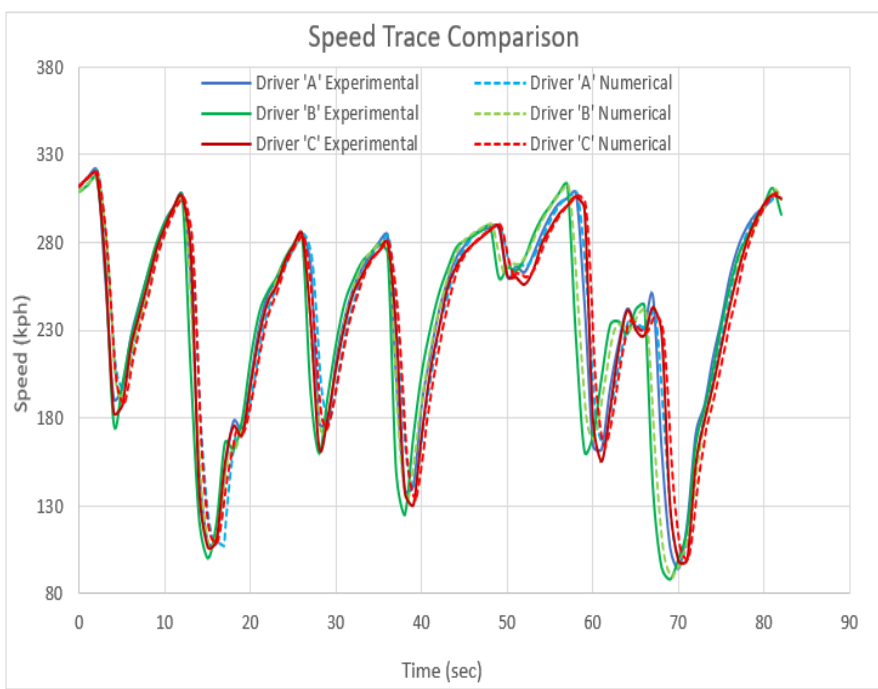

Figure 2. Speed Trace Comparison between 3 drivers from numerica simulations and derived data from F1 TV App

In order to evaluate the performance of ERS, the model considered the following: The gear ratio between the engine crankshaft and MGU-K is set to 4 from the initial chosen value of 3.33 as the fuel flow rate dictates the max power output of the engine. The battery pack configuration is set to 100 cells (out of which 20 cells are in series and 
there are 5 stacks of the same put in parallel) rather than 140 cells in series after simulations and optimising the battery sizing and capacity [7]. Controllers were also added in ES block as math functions to ensure that the difference between the maximum and minimum SOC of the battery pack would never exceed $4 \mathrm{MJ}$ at any point of time during the lap. The motive behind this was to make sure the model is following the regulations at all times and to run the system optimised for energy recovery and deployment.

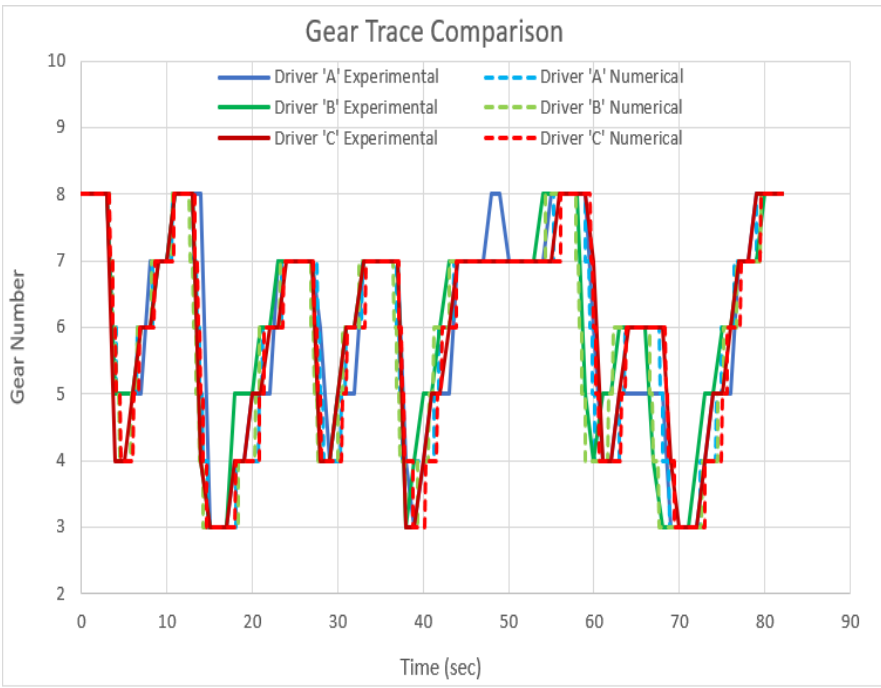

Figure 3. Gear Trace Comparison between 3 drivers from numerical simulations and derived data from F1 TV App

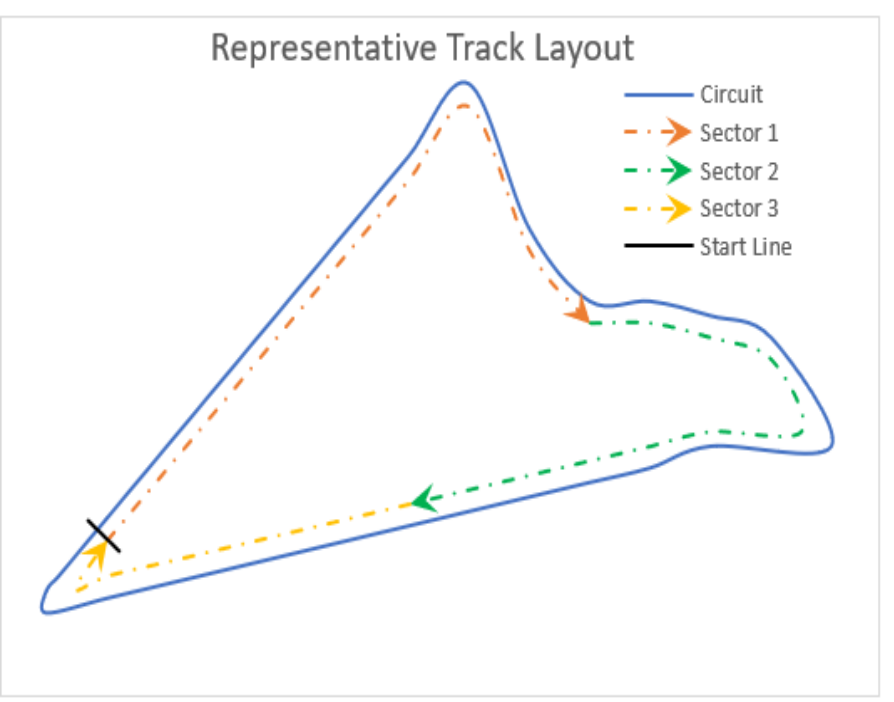

Figure 4. Representative Track Layout for illustrative purposes

A representative track layout is shown in Figure 4 in order to give a brief outlook of how the analysis is carried out. Figure 4 is used for representative and illustrative purposes only. The whole circuit is divided into 3 sectors with sector 1 beginning from the start line and sectors 2 and 3 following as shown in Figure 4.

\section{Positive Kinetic Energy}

Positive Kinetic Energy (PKE) can be defined as the positive kinetic energy per unit distance [36]. The equation for estimating PKE has been proposed in [37] [38] as follows:

$$
P K E=\frac{\sum\left(V_{f}^{2}-V_{i}^{2}\right)}{X} \text { for } \mathrm{V}_{\mathrm{f}}>\mathrm{V}_{\mathrm{i}}
$$

where,

$V_{f}-$ Final Vehicle Speed

$\mathrm{V}_{\mathrm{i}}$ - Initial Vehicle Speed

$\mathrm{x}$ - Distance Travelled

PKE is a widely used method in automotive testing and is considered as one of the good indicators of variation in fuel consumption and emission levels. However, the biggest advantage of using PKE in our case is that we can compare the driving styles that are unique to individual drivers to better understand driver to driver variation and their effects on lap times. Although PKE has the units of acceleration, it cannot be compared to mean acceleration as PKE is closely regarded as the average energy contribution that is required to accelerate and decelerate the vehicle [39].

\section{Simulation and Results}

\section{Analysis of MGU-K energy recovered and PKE}

The model is run for analysing the ERS and evaluating the strategies used by different drivers during qualification. The circuit is divided in 3 sectors as mentioned in the FIA circuit map [40]. From the onboard telemetry data [28], the sector times of each driver is extracted and highlighted as a Point of Interest (POI) in the model output. Since the distance covered by the drivers is the same for individual sectors, the difference in sector times highlight the energy deployment and recovery capabilities of each car. Since the model is used to determine instantaneous values of parameters, integrators are used to determine the total value from start until the POI. The energy recovered by the MGU-K in each sector is analysed to determine the energy available for deployment for the whole lap.

Another way of validating this estimation is the comparative analysis of the PKE of the drivers [41]. Since MGU-K works on the same principle of Kinetic Energy Recovery System (KERS), comparison of energy recovery by MGU-K with PKE would yield better insight from the dynamics of each car and driver. In principle, higher the PKE, higher energy will be recovered and as well as deployed by the system. Since the regulations limit the maximum power recovered at any instant by the MGU-K to $120 \mathrm{~kW}$ even though the braking power is as high as $1200 \mathrm{~kW}$ (analysed from the full car model), it is clear that significant proportion of energy generated by braking is still going as wasted heat energy.

The analysis is divided in 3 types:

a. Same Team but Different Driver (STDD): Since there are 10 teams in the 2019 FIA Formula One World Championship ${ }^{\circledR}[42]$ and each team is allowed to have 2 race drivers, the effect of driver to driver variation on their lap time is analysed as the car and engine is practically the same for both the drivers

b. Same Power-Unit but Different Team (SPDT): Since there are 4 PU suppliers for the 2019 FIA Formula One World Championship ${ }^{\circledR} \quad$ [43], a comparative analysis of ERS 
performance for different teams with the same PU can be carried out

c. Energy Recovered and PKE for All Drivers: A comparative analysis of the energy recovered and PKE in each sector is done for all the drivers at the end of qualification to gain a better insight of the trend and correlation between energy recovery and PKE

For each of the following analysis, the data is normalized for comparison so that a percentage increase or decrease in values can be evaluated. The sectors are denoted as ' $\mathrm{S}$ ', drivers as 'D', MGU-K energy recovered as 'MGU-K', Positive Kinetic Energy as 'PKE' and since the analysis is done for each sector individually and the whole lap, the denotation of 'Full' corresponds to whole lap analysis. The post-processing of the plots is done by defining driving states as outlined in Table 1.

Table 1. Driver mode definition adopted with the inference from plots

\begin{tabular}{|l|l|l|r|}
\hline Case & $\begin{array}{l}\text { MGU-K } \\
\text { Recovery }\end{array}$ & PKE & $\begin{array}{r}\text { Inference from Plots (Low=Any value } \\
<1 ; \text { High=1) }\end{array}$ \\
\hline 1 & Low & Low & Balanced \\
\hline 2 & Low & High & Recovery \\
\hline 3 & High & Low & Recovery and Deployment \\
\hline 4 & High & High & \\
\hline
\end{tabular}

'Balanced' mode of driving refers to the inference that the drivers are deploying and recovering energy in equal amount which attributes to the fact that the ERS is used as an energy flow device rather than an energy storage device. 'Deployment' mode of driving refers to the inference that the drivers are deploying more energy and recovering less which attributes to the fact that the ERS is being used as an energy depletion source. 'Recovery' mode of driving refers to the inference that the drivers are recovering more energy and deploying less which attributes to the fact that the ERS is being used as a storage device rather than an energy flow device. Lastly, 'Recovery and Deployment' mode of driving refers to the inference that the ERS is pushed to the limit for maximum performance with high rates of recovering and high rates of deployment attributing to the fact that ERS is used as power flow device rather than storage device.

\section{Same Team but Different Driver (STDD)}

The analysis is carried out for 9 teams as driver data is extracted for 19 drivers with the 20th driver data being inconsistent. Typically considering that since it is the same team, both the drivers of the team have the same car from an ERS and PU standpoint. So, the best way to differentiate the performance of the ERS would be to analyse the driver to driver variation. This gives an insight about how drivers have driving styles and how this style effects the ERS capabilities of the car. For ease of understanding, the analysis of one team is shown below in Figure 5 and 6. The readers can refer to Appendix I for plots of other teams. The basis for comparison here is the preferred modes that is used by drivers for the individual sectors and the whole lap. Based on this, a summary graph is plotted depicting the percentage of different modes used by different drivers and the most preferred modes used by drivers.

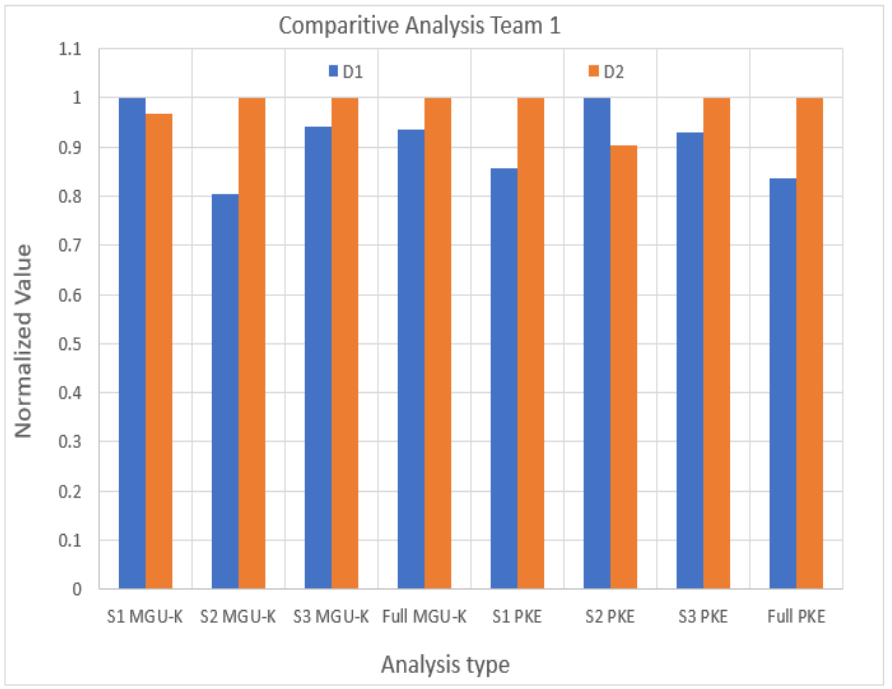

Figure 5. Comparative analysis of MGU-K and PKE capabilities of one of the teams for driver to driver variation insights (S1: sector 1, S2; sector 2 and S3: sector 3)

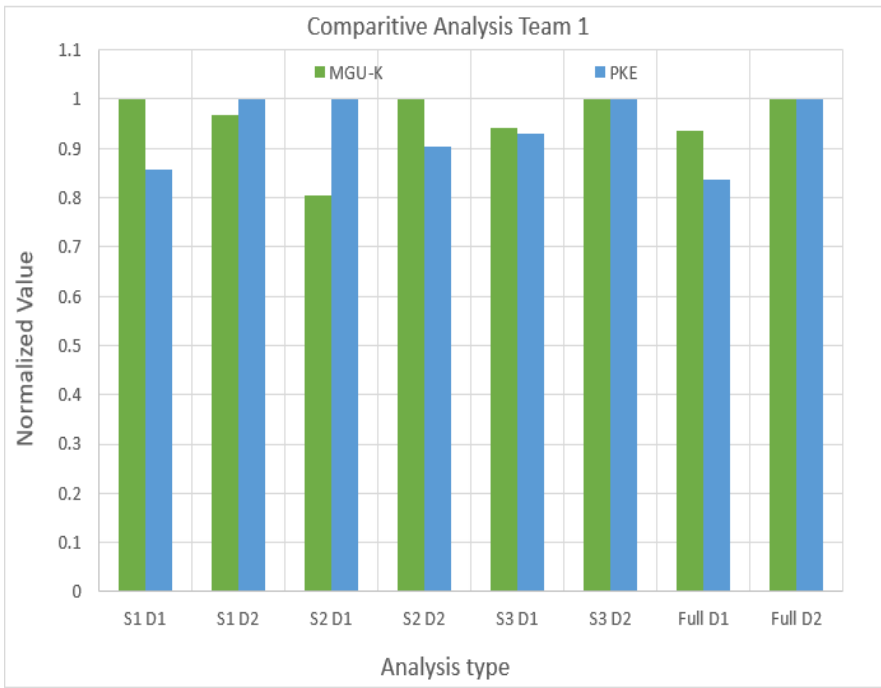

Figure 6. Comparative analysis of drivers from the same teams to estimate the deployment and recovery potential of their cars in different sectors of the track Strategies Used by Different Drivers

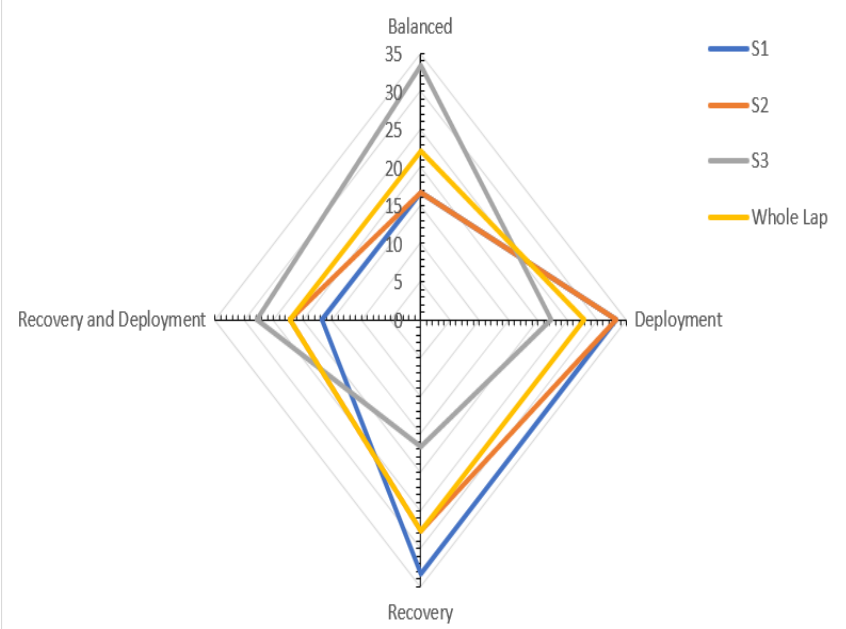

Figure 7. Summary plot of modes used by all the 19 drivers from STDD analysis in terms of percentage 
From Figure 7, it can be clearly seen that every driver has their own unique style of driving. Even though the drivers within the same team have almost identical cars, their style of driving, recovery and deployment strategies used are significantly different (Figure 5 and 6). From the radar plot (Figure 7), it can be seen that the majority of the drivers use more of the recovery mode in the 1st sector, more of the deployment mode in the 2nd sector and more of the balanced mode in the 3rd sector. For the whole lap analysis, the trend follows equally towards using more recovery or more deployment. An interesting point to note here is that even though the maximum performance from the ERS can be obtained by using the recovery and deployment mode, it is not the most preferred mode for the drivers as the amount of energy recoverable is less than the amount of energy that can be deployed. Hence the preferred mode of drivers is largely targeted towards recovery, deployment and balanced.

The comparative analysis between drivers within each team provides a baseline for teams to understand how much energy can be extracted and deployed by each of their drivers and which mode of driving is best suited to optimise the ERS performance. However, this analysis fails to compare how drivers from opponent teams with same or different PU compare against each other. Since other factors like aerodynamics, vehicle dynamics, vehicle setup, types of tires used, all play a role in this case, the comparison becomes more of qualitative rather than quantitative. For better understanding of the car's performance from purely an ERS perspective, a comparative analysis between the drivers is carried out who have the same PU as well as all the 19 drivers together. Since there is a constant strive for any team to put out their best performance, competitor analysis plays a crucial role in understanding the dynamics of other cars, ERS benchmarking and potential strategies that can be used to maximize the car's performance. These analyses yield valuable information to the teams in terms of their standing on the grid and the improvements that can be done to the car as the season progresses.

\section{Same Power-Unit Different Team (SPDT)}

An analysis is carried out for the MGU-K energy recovery and PKE of the drivers that have the same PU but drive for different teams. This is done in order to differentiate the performance capabilities of teams from an ERS standpoint. Initially, the assumption was taken that only the analysis of MGU-K energy recovery would be enough to compare the drivers as the data acquired from STDD analysis would aid this understanding. However, the motive for analysing the PKE performance of the drivers was that the deployment side of ERS largely remains unknown with the recovery analysis. Again, for ease of understanding, the analysis of one PU manufacturer is shown. The readers can refer to Appendix II for plots of other PU manufacturers. Sector wise analysis of the all the drivers driving with PU 1 is presented below in Figure 8 and 9. The plots are divided into 2 parts with the first parts giving insights into purely the MGU-K energy recovered and the other part giving insights into the PKE of drivers. This is done in order to ease the understanding and for comparative analysis between different PU manufacturers. Summary plots are presented in order to obtain a correlation between certain sector performance to the whole lap performance for PU manufacturers in order for teams to take advantage in those particular sectors of the track. In order to maximize the performance of the car, teams should look closely into optimising and maximizing this sector's performance. These plot results are then compared against the STDD plots for a better understanding of the dynamics that PU plays in a particular car's performance.

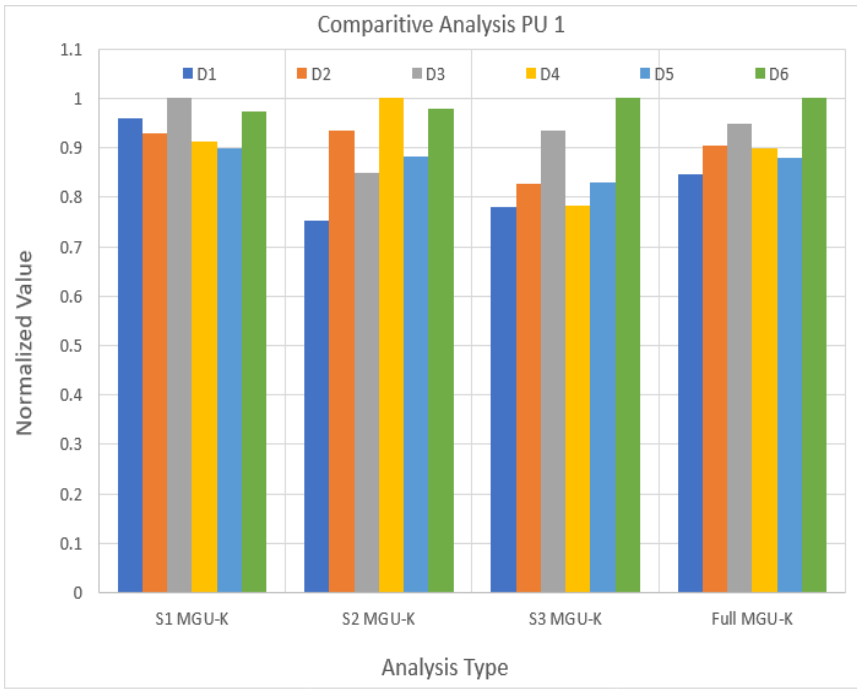

Figure 8. MGU-K recovery potential comparison of all drivers using PU1 for each sector as well as for the whole lap

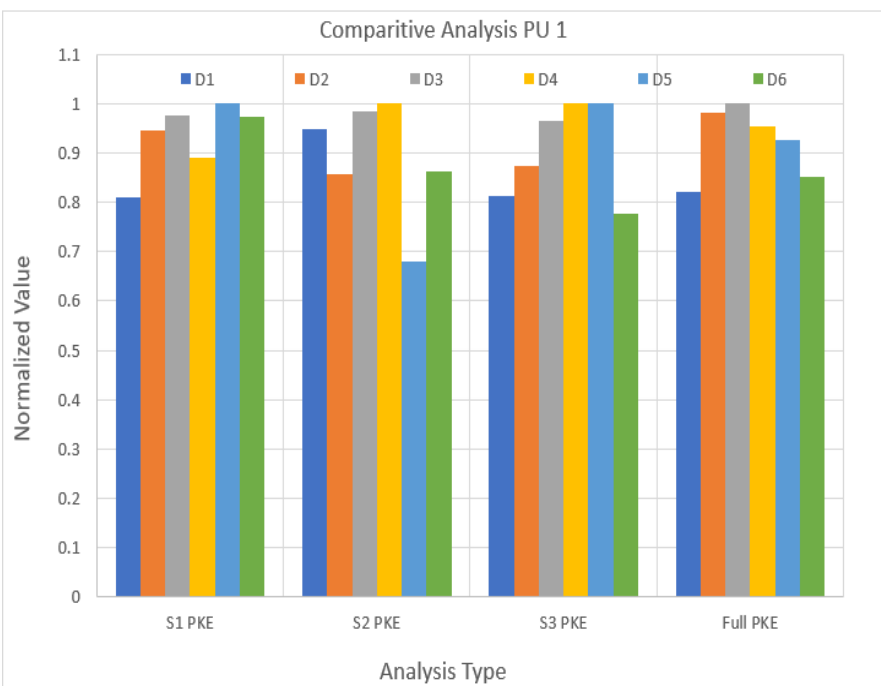

Figure 9. PKE comparison of all drivers using PU1 for each sector as well as for the whole lap

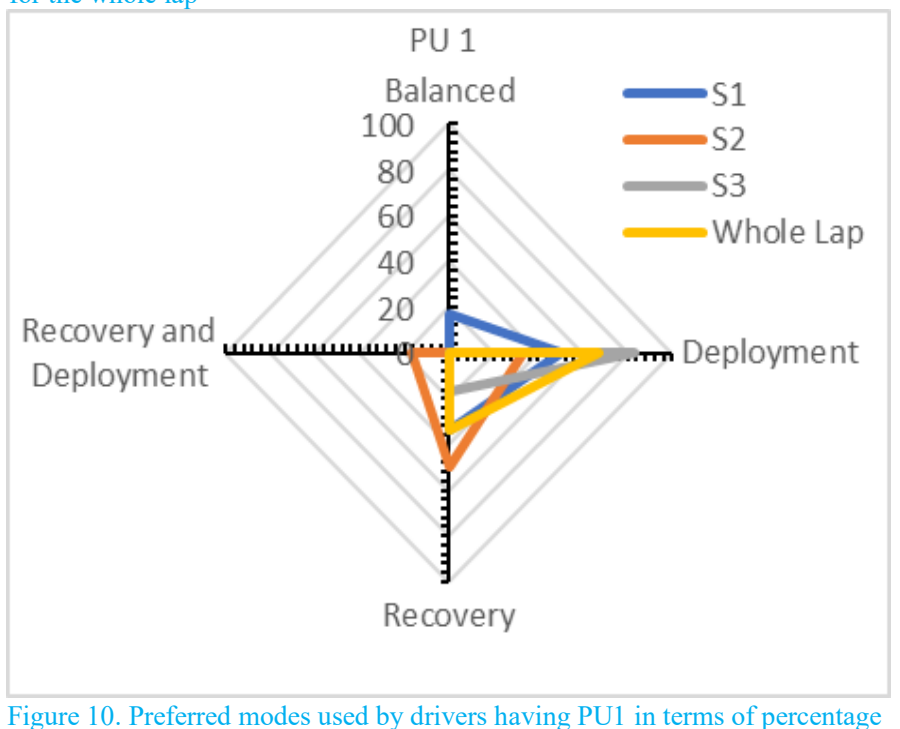




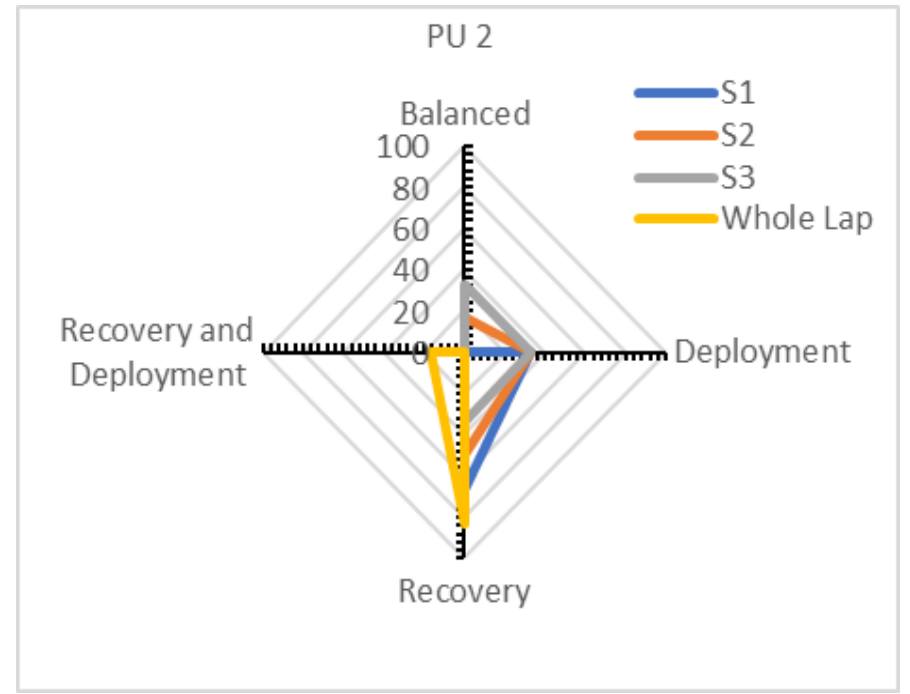

Figure 11. Preferred modes used by drivers having PU2 in terms of percentage

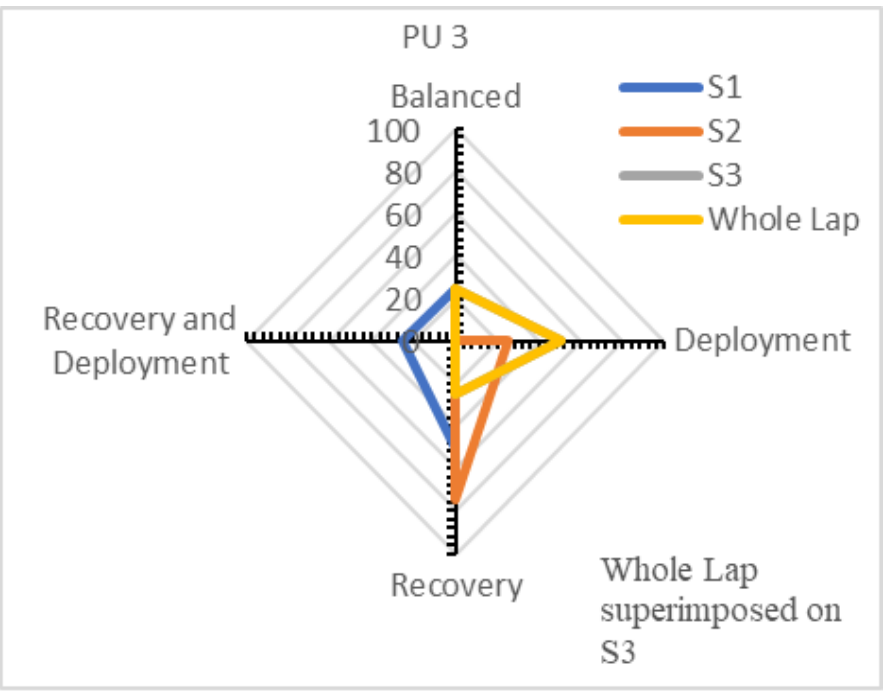

Figure 12. Preferred modes used by drivers having PU3 in terms of percentage

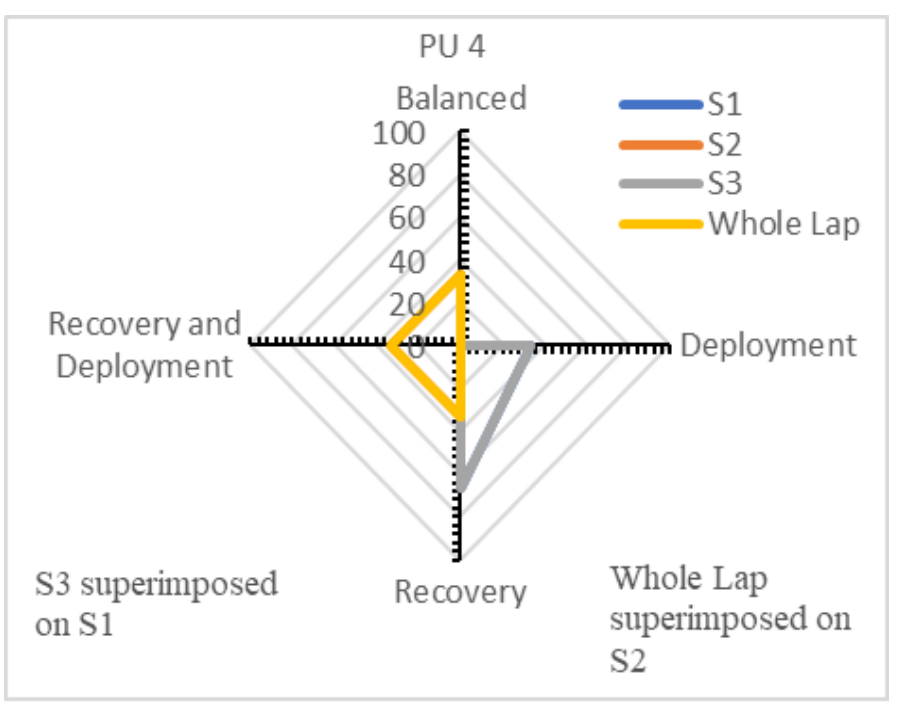

Figure 13. Preferred modes used by drivers having PU4 in terms of percentage

It can be seen that the SPDT radar plots shown in Figure 10, 11, 12, 13 are very different compared to the STDD radar plot given in Figure 7. There are 2 interesting parameters that are highlighted by the SPDT plots: the preferred mode used by the teams having the same PU and the sector of the track that is a representative plot of the car's performance for the whole lap (the most critical sector that needs to be optimised). The plots show that teams have different preference in the modes used for different sectors and for the whole lap like teams using PU 1 have more affinity to use deployment mode, teams using PU 2 have more affinity to use recovery mode, teams using PU 3 as well as teams using PU 4 have more affinity to use a mixture of recovery, deployment and recovery and deployment modes. It can also be seen that the percentage of different modes used by teams having one PU configuration is contrasting to the teams using another PU configuration for any sector. This highlights the strong variance in modes used by different teams from an PU and ERS outlook.

Another interesting finding was the sector characterisation in the track for different PU configurations that is a representative plot of the whole lap performance. This basically highlights performance of the ERS in a sector which closely follows/mimics the vehicle's performance for the whole lap. This has 2 advantages: the teams can target the best possible performance in this sector to maximize the ERS performance and the teams can layout a baseline for comparisons against other teams as to which sector is the best for other teams and where can the performance gains be increased.

This means that sector 1 is the strong point for teams using PU 2, sector 2 is the strong point for teams using PU 4 and lastly sector 3 is the strong point for teams using PU 1 and 3 . However, there is always a trade-off here because if the ERS performance is maximized for a particular sector, it may cause a relatively poor performance in the other sectors as the strategies focus on only that one particular sector optimisation. Hence a balance of everything must be looked into. With this information, the engineers can develop strategies to encapsulate the pros and cons of using different modes in each sector to maximize the ERS performance and gain a competitive edge against other teams. The SPDT analysis neglects the fact that even though some teams have the same PU, the other factors affecting the performance of the car such as driver to driver variation (which can be obtained from STDD analysis), aerodynamics, vehicle dynamics and tire usage may drastically vary. This presents the specific use of this analysis and its limitations.

\section{Energy Recovered and PKE for All Drivers}

In order to understand how one driver's ERS strategy differs from another driver, a comparative analysis of MGU-K energy recovered and PKE is carried out for all the 19 drivers. This way, a general trend of modes and strategy used by drivers can be established independent of the team, car and PU used. This analysis also highlights the capabilities of the ERS for current regulations and how best the drivers make use of the additional power that it provides. The plots are normalized against the driver that has recovered (MGU-K case) or deployed (PKE) the maximum energy for each sector and for the whole lap. Radar plots have been used as in the previous cases to understand the trends of modes used and the percentage of modes used in each sector and the whole lap. These plots are compared against the radar plots of STDD and SPDT analysis to propose an optimal strategy that can be used by teams to maximize performance. 


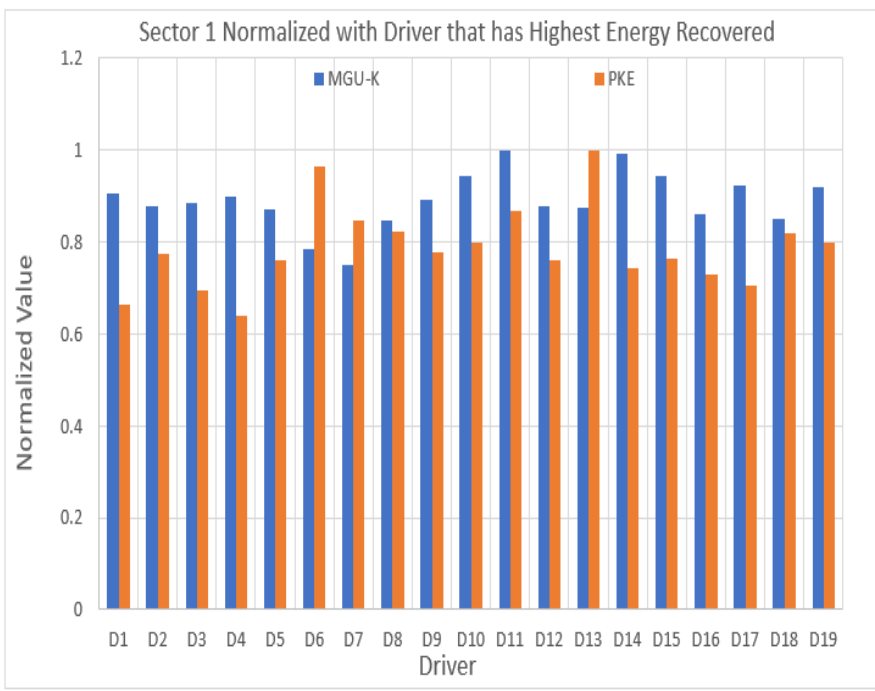

Figure 14. Comparative analysis of MGU-K and PKE potential of all the drivers for sector 1 of the track

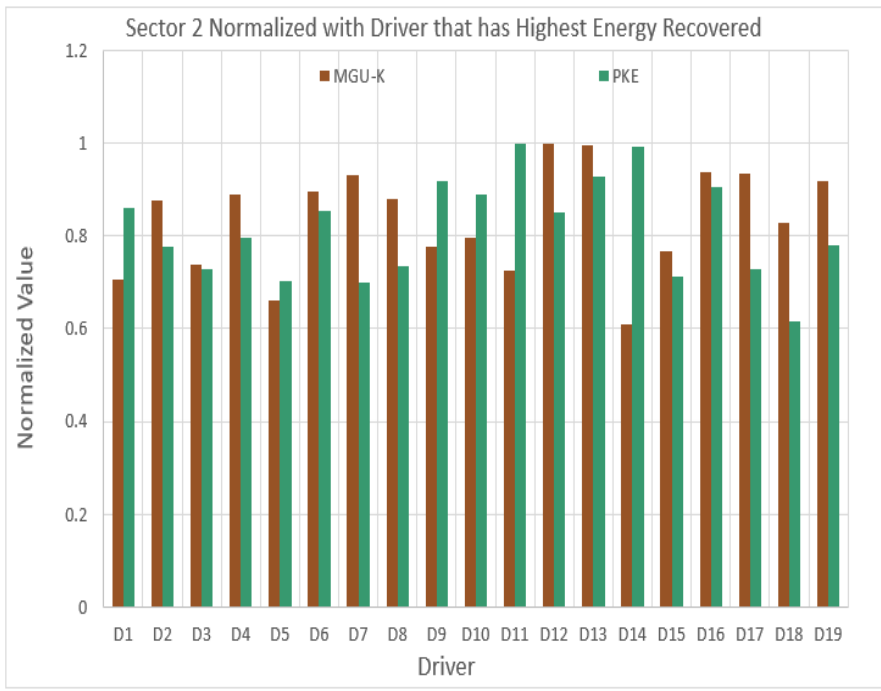

Figure 15. Comparative analysis of MGU-K and PKE potential of all the drivers for sector 2 of the track

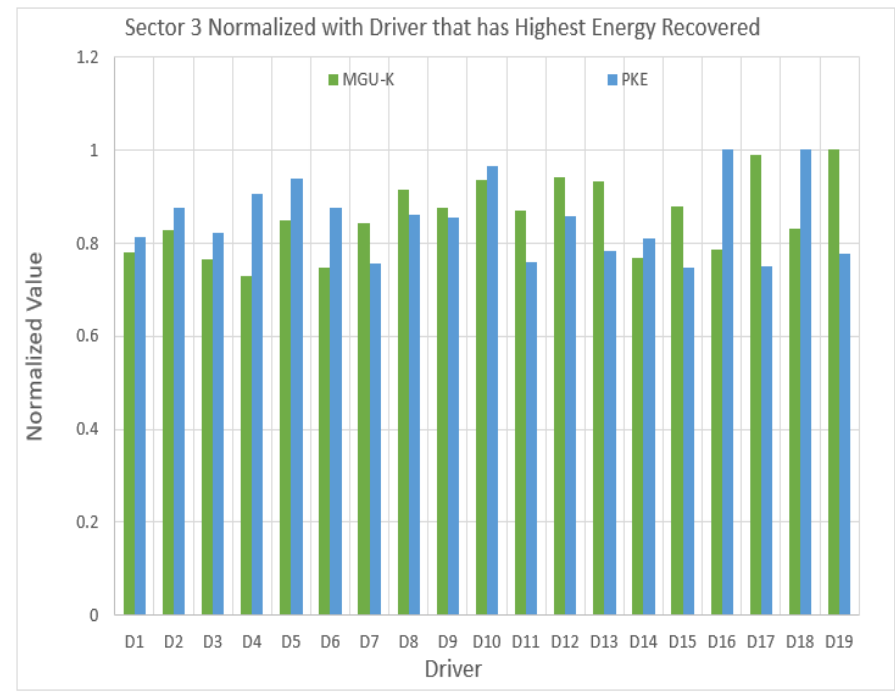

Figure 16. Comparative analysis of MGU-K and PKE potential of all the drivers for sector 3 of the track

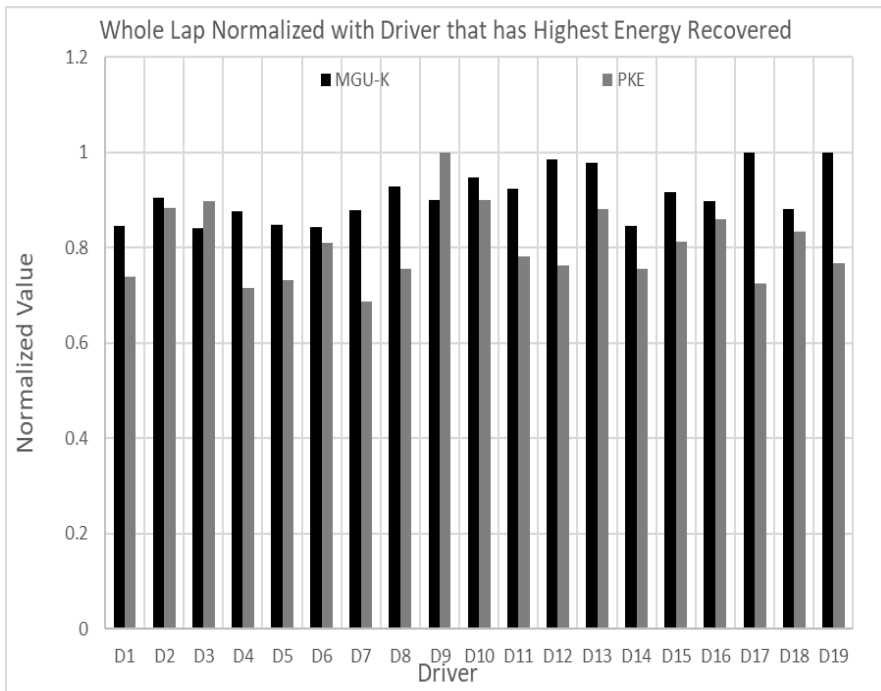

Figure 17. Comparative analysis of MGU-K and PKE potential of all the drivers for the whole lap

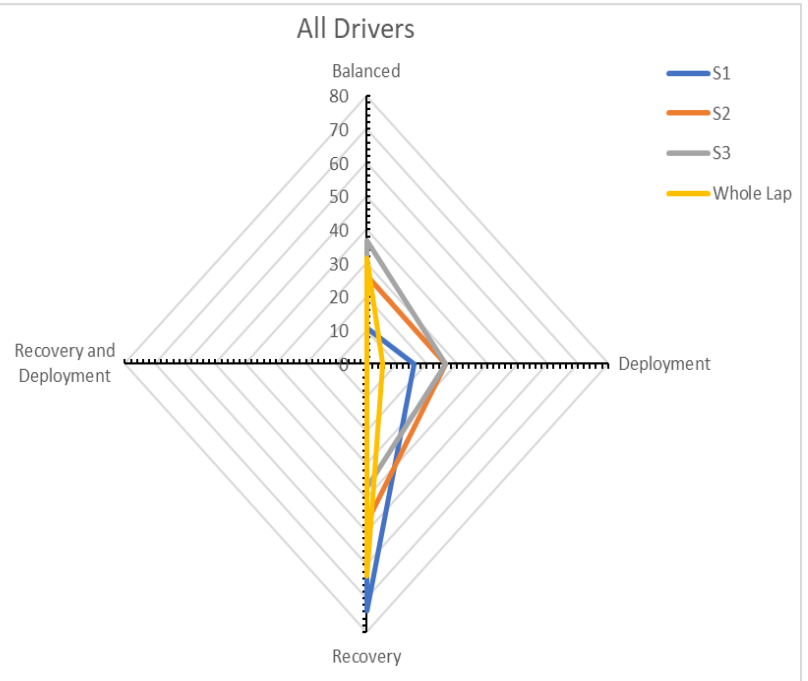

Figure 18. Summary plot of modes used by all the drivers in terms of percentage

The plots in Figure 18 clearly depict affinity of the drivers to use more of recovery mode for almost all the sectors and the whole lap. Also, for sector 2 and sector 3 , there is a trend of using balanced mode for a lot of drivers. Comparing these plots against STDD and SPDT, one can infer a strong correlation for drivers to use recovery mode for sector 1 and balanced mode for sector 3. However, there is a variance in the mode of choice to be used for optimising performance in sector 2 . From a technical perspective, in order to balance the energy, the optimal mode to be used for sector 2 should be deployment which is inferred from the summary plots in Figure 7. This strong variance emphasises the effect of other factors which affect the car's performance. One of the major reasons for the variance in sector 2 ERS performance which the authors could understand from the analysis is the conditions imposed on the MGU-K recovery controller in the model. As the regulations limit the recovery to $2 \mathrm{MJ}$ per lap and the model is set to recover unlimited energy whilst keeping other constraints imposed (in order to understand the ERS capabilities of the car), there are scenarios where some drivers can recover a little more than $2 \mathrm{MJ}$ of energy throughout the lap and some drivers are able to recover a lot more than $2 \mathrm{MJ}$ of energy throughout the lap. 


\section{Conclusion}

The present work aimed to understand the dynamics of ERS of a Formula One car. This is done in order to maximize the qualification performance of an F1 car using the data obtained from the first calendar race of the 2019 FIA Formula One World Championship ${ }^{\circledR}$. The data for 19 drivers is extracted from F1 TV to get their lap time trace, gear shift speeds, engine speeds and deduce other important parameters. This data is then fed to the V6 engine and full car model that was developed in our previous work [7] to estimate the ERS performance of different teams, PU manufactured and drivers.

The circuit analysed is divided into 3 sectors and the performance of the PU was analysed for both the whole circuit and individual sectors. The analysis is carried out from purely an PU and ERS standpoint for the energy transfer between the MGU-K and ES. The use of PKE is incorporated to estimate the deploying capabilities of the car and the full car model is used to estimate the recovery capabilities of the car.

From the STDD analysis it was found that the driving style of every driver is unique in their own way and is a critical parameter in determining their PU's performance and ultimately their position at the end of qualification. The STDD analysis depicted that even though the drivers have the same car and PU, their driving style and choice of modes are completely different. $1 / 3^{\text {rd }}$ of the drivers preferred to use deployment mode for sector 1 , recovery mode for sector 2 and balanced mode for sector 3 .

From SPDT analysis, individual sectors are identified which are a representation of the car's performance for the whole circuit for different PU manufacturers. In order to maximize performance, the teams should work towards maximizing their car's performance in these sectors which in turn will optimize their car's performance for the whole circuit. Results illustrate that teams using PU1 and PU3 are better off in sector 3, teams using PU2 are better off in sector 1 and lastly teams using PU4 are better off in sector 2 .

Energy recovery and PKE analysis is carried for all the drivers to capture the trend and correlation between energy recovery and PKE. A deviation was found in this analysis when comparing to the results of STDD analysis in terms of the most preferred mode of choice of drivers for sector 2 . In order to find the root-cause of this deviation, a more in-depth analysis needs to be carried out for other circuits as well. This would allow the engineers to benchmark and optimize the ERS setup as the regulations [12] allow for limited number of PU element changes throughout the season. The approach proposed in this work is accurate for estimating the ERS capabilities of an F1 car. Engineers can adopt this methodology to estimate their car's performance with previous year's data to get a better understanding of areas in which their cars can be improved and optimized for future races.

\section{References}

1. Lambert S (2013) ADVANCING THE DEVELOPMENT OF HYBRID ELECTRIC VEHICLES IN MOTORSPORT. PhD. The University of Warwick

2. Turner, J. and Pearson, R., "The Application of Energy-Based Fuel Formulae to Increase the Efficiency Relevance and Reduce the CO2 Emissions of Motor Sport," SAE Technical Paper 200801-2953, 2008, doi:10.4271/2008-01-2953
3. Otero, V.T. and Samuel, S., "Numerical Simulation of a 2018 F1 Car Cooling System for Silverstone Circuit," SAE Technical Paper 2018-01-0169, 2018, doi:10.4271/2018-01- 0169

4. Formula One Technical Regulations 2006. [Online] Available at: https://argent.fia.com/web/fiapublic.nsf/035E7BF2DE8E684CC12573290033747B/\$FILE/07 F1_TECHNICAL_REGULATIONS.pdf?Openelement

5. Formula One Technical Regulations 2009. [Online] Available at: https://argent.fia.com/web/fiapublic.nsf/7C4F8D883039AF6AC125757D00369C58/\$FILE/12009 F1_TECHNICAL_REGULATIONS ShowingAlterations 17-03-2009.pdf

6. Re-writing the F1 rulebook - Part 4: 'cleaner' cars, KERS and the return of slicks. [Online] Available at:

https://www.formula1.com/en/latest/article.re-writing-the-f1rulebook-part-4-cleaner-cars-kers-and-return-ofslicks.1NUrjfG83a6aE0QSuAkGK8.html

7. Bopaiah, K. and Samuel, S., "Strategy for Optimizing an F1 Car's Performance Based on FIA Regulations," SAE Int. J. Advances \& Curr. Prac. in Mobility 2(5):2516-2530, 2020, doi:10.4271/2020-01-0545.

8. Understanding F1 ERS. [Online] Available at: https://www.formula1.com/en/championship/insidefl/understanding-fl-racing/Energy Recovery Systems.html.

9. F1 Power Unit and ERS Rules. [Online] Available at: https://www.formula1.com/en/championship/inside-fl/rulesregs/Power Unit and ERS.html.

10. Formula One Technical Regulations 2019. [Online] Available at: https://www.fia.com/sites/default/files/2019 technical regulatio $\underline{\text { ns - 2019-03-12.pdf }}$

11. Edmondson L (2017) Is an F1 car more energy efficient than an electric vehicle? [Online] Available at:

http://www.espn.co.uk/fl/story//id/15152695/is-f1-car-moreenergyefficient-electric-vehicle

12. Formula One Sporting Regulations 2019. [Online] Available at: https://www.fia.com/sites/default/files/2019 sporting_regulation s-2019-03-12.pdf

13. Elias, G., Samuel, S., and Picarelli, A., "Performance of Ancillary Systems of 2014+ Le Mans LMP1-H Vehicles and Optimization," SAE Technical Paper 2015-01-1163, 2015, doi:10.4271/2015-01-1163

14. UK Government, Gov.Uk. [Online] Available at: https://www.gov.uk/government/uploads/system/uploads/attach ment_data/file/446487/dukesa_1-a 3.xls.

15. Five-examples-why-f1-is-accelerating-the-future. [Online] Available at:

https:/www.mercedesamgf1.com/en/news/2018/10/insight-fiveexamples-why-fl-is-accelerating-the-future/

16. BorgWarner 9180 Turbo Specifications. [Online] Available at: https://cdn.borgwarner.com/docs/default-source/iam/boostingtechnologies/efr-9180-d.pdf?sfvrsn=f45ab03c 17

17. Engauge Digitizer, markummitchell, 2019, doi: 10.5281/zenodo.3558440.

18. Ludvigsen, K., Classic Racing Engines (Sparkford: Haynes, 2002).

19. Muta, K., Yamazaki, M., and Tokieda, J., "Development of New-Generation Hybrid System THS II - Drastic Improvement of Power Performance and Fuel Economy," SAE Technical Paper 2004-01-0064, 2004, doi:10.4271/2004-01-0064 
20. Ayers, C W. Tue. "Evaluation of 2004 Toyota Prius Hybrid Electric Drive System Interim Report". United States. doi:10.2172/885776. https://www.osti.gov/servlets/purl/885776

21. Hsu, J S. Report on Toyota/Prius Motor Torque-Capability, Torque-Property, No-Load Back EMF, and Mechanical Losses. United States: N. p., 2004. Web. doi:10.2172/885669

22. Bengolea, F. andSamuel, S., "Technology Choices for Optimizing the Performance of Racing Vehicles," SAE Technical Paper 2016-01-1173, 2016, doi:10.4271/2016-011173.

23. 2014 Formula One Power Unit Regulations Leaflet. [Online] Available at: https:/www.fia.com/sites/default/files/publication/file/FIA $\% 20 \mathrm{~F}$ 1\%20Power\%20Unit\%20leaflet.pdf

24. F1 lap records. [Online] Available at: https://f1.fandom.com/wiki/Lap Record

25. On-Board Telemetry Data. [Online] Available at: https://f1tv.formula1.com/en/.

26. Recognize Text Using OCR. [Online] Available at: https://in.mathworks.com/help/vision/examples/recognize-textusing-opticalcharacter-recognition-ocr.html.

27. OCR MATLAB Documentation and Description. [Online] Available at: https://in.mathworks.com/help/vision/ref/ocr.html.

28. Event and Timing Information. [Online] Available at: https://www.fia.com/events/fia-formula-one-worldchampionship/season-2019/eventtiming-information-1

29. Perrinn, "PERRINN wiki.," 2019, [Online] Available at: https://docs.google.com/document/d/1IjmDbmcW2IDg5Kj9ENp Y3 FwoHv3RCJ2f8ZJdbjRpk/pub\#h.faulr6622qmi.

30. Brown, C., Making Sense of Squiggly Lines (Huntington Beach, CA: Christopher Brown Racing, 2011), 26.

31. Ogawa, A., Yano, S., Mashio, S., Takiguchi, T., Nakamura, S., Shingai, M.: Development Methodologies for Formula One Aerodynamics, Honda R\&D Technical Review 2009, F1 Special (The Third Era Activities), p. 142-151

32. Ogawa, A., Mashio, S., Nakamura, D., Masumitsu, Y.,Minagawa, M., Nakai, Y.: Aerodynamics Analysis of Formula One Vehicles, Honda R\&D Technical Review 2009, F1 Special (The Third Era Activities), p. 152-162

33. Shibue, H., Taneda, K., Kitaki, Y.: Technologies for Enhancement of Dynamic Performance of Formula One Vehicle, Honda R\&D Technical Review 2009, F1 Special (The Third Era Activities), p. 163-171

34. A. J. Tremlett \& D. J. N. Limebeer (2016) Optimal tyre usage for a Formula One car, Vehicle System Dynamics, 54:10, 14481473, DOI: 10.1080/00423114.2016.1213861

35. F1 2021 Hinted Regulations. [Online] Available at: https://www.formula1.com/en/latest/article.formula-1-in-2021where-we-stand-andwhat-happensnext.3f4zgyDjeERMFtxaymbncK.html.

36. Konstantas, G. and Stamatelos, A. (2004) 'Quality assurance of exhaust emissions test data', Proceedings of the Institution of Mechanical Engineers, Part D: Journal of Automobile Engineering, 218(8), pp. 901-914. doi: $10.1243 / 0954407041581075$.

37. Watson, H.C., and E.B. Milkins. "An International Drive Cycle," 21st FISITA Congress. Belgrade, Yugoslavia. June 1986.

38. Webster, W.J., and C. Shih. "A Statistically Derived Metric to Monitor TimeSpeed Variability in Practical Emission Testing."
Presented at 6th CRC Conference, San Diego, CA. March 15,1996 .

39. Watson, H., "Effects of a Wide Range of Drive Cycles on the Emissions from Vehicles of Three Levels of Technology," SAE Technical Paper 950221, 1995, https://doi.org/10.4271/950221

40. 2019 AUSTRALIAN GRAND PRIX Circuit Map. [Online] Available at: https://www.fia.com/sites/default/files/doc 1 _2019_australian_grand prix_-_circuit_map_0.pdf

41. Crawford, James A., Corey Jordan and George B. Dresser. "MODAL EMISSIONS MODELING WITH REAL TRAFFIC DATA.” Research Report 1358-3F (1999)

42. 2019 F1 GRID. [Online] Available at: https://www.formula1.com/en/latest/article.in-full-all-thedrivers-on-the-2019-formula-1grid.2UuZsxj5FmAMEeYEYYWcAM.html

43. 2019 F1 Teams. [Online] Available at: https://www.formula1.com/en/results.html/2019/team.html

\section{Nomenclature}

\begin{tabular}{|c|r|}
\hline MGU-K & Motor Generator Unit-Kinetic \\
\hline $\mathrm{PKE}$ & Positive Kinetic Energy \\
\hline $\mathrm{P}$ & Power \\
\hline$\dot{\mathrm{m}}_{\text {fuel }}$ & Mass flow rate of fuel \\
\hline$\eta_{\mathrm{b}-\text { thermal }}$ & Brake Thermal efficiency \\
\hline $\mathrm{Q}_{\mathrm{HV}}$ & Calorific value \\
\hline$\lambda$ & Lambda \\
\hline$r_{\text {intake pressure }}$ & Pressure Ratio \\
\hline$\dot{\mathrm{m}}_{\text {air }}$ & Mass flow rate of air \\
\hline$\dot{\mathrm{m}}_{\text {air,NA }}$ & Mass flow rate of air for a naturally aspirated engine \\
\hline$\omega_{\text {engine }}$ & Vehicle Speed \\
\hline$V_{\text {vehicle }}$ & Transmission Ratio \\
\hline$i_{o} i_{\theta}$ & Radius of Tyre Corrected \\
\hline$r_{\text {tyre }}$ & Final Velocity \\
\hline $\mathrm{V}_{\mathrm{f}}$ & Initial Velocity \\
\hline $\mathrm{Vi}$ & Distance Travelled \\
\hline $\mathrm{x}$ & Sector \\
\hline $\mathrm{S}$ & Driver \\
\hline $\mathrm{D}$ & $\mathrm{PU}$ \\
\hline
\end{tabular}

\section{Contact Information}

\section{Karan Bopaiah}

Auburn University, Alabama, USA

karanbopaiah@gmail.com

\section{Stephen Samuel}

Oxford Brookes University, Oxford, United Kingdom s.samuel@brookes.ac.uk 
Appendix I
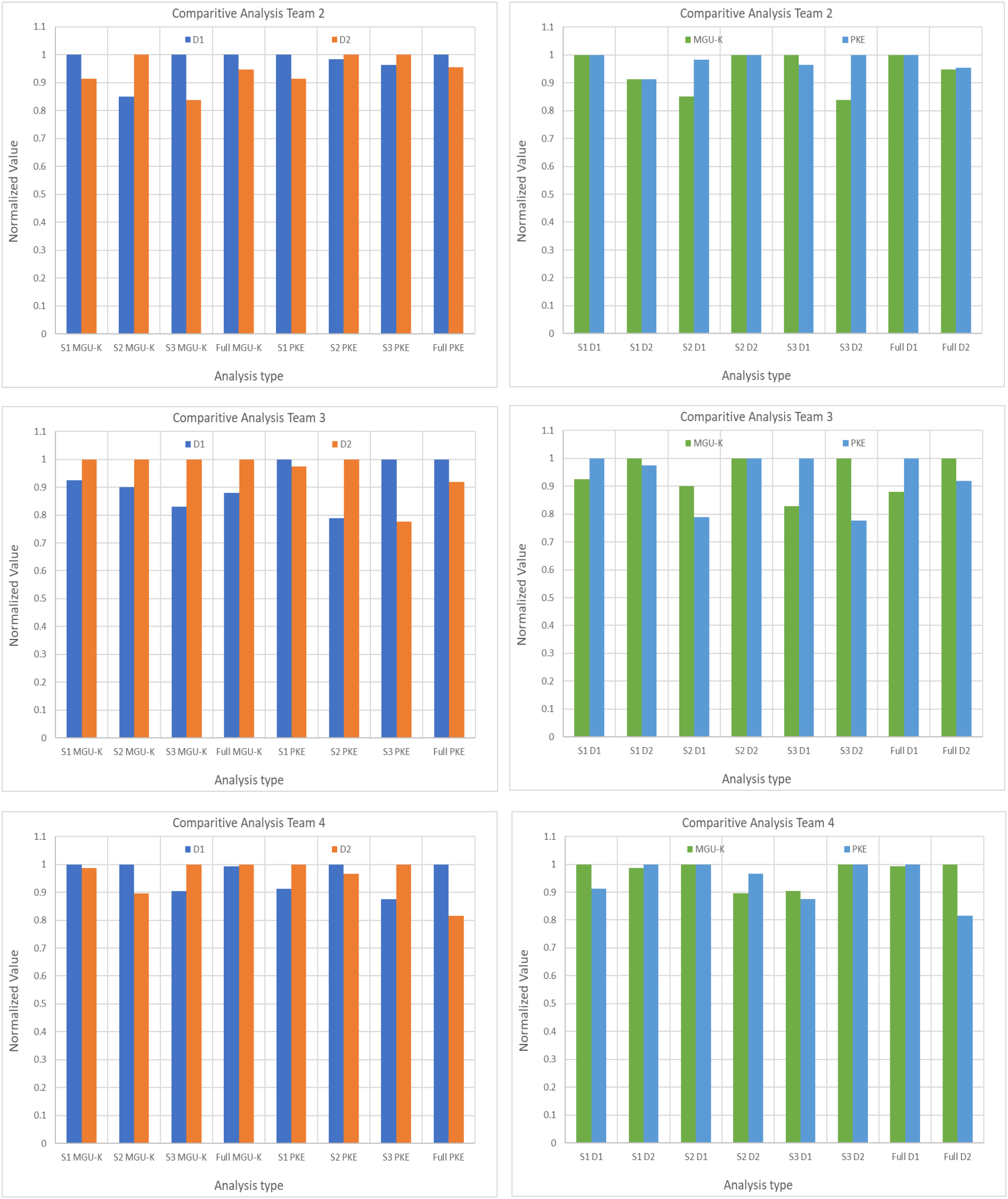

Page 11 of 14 

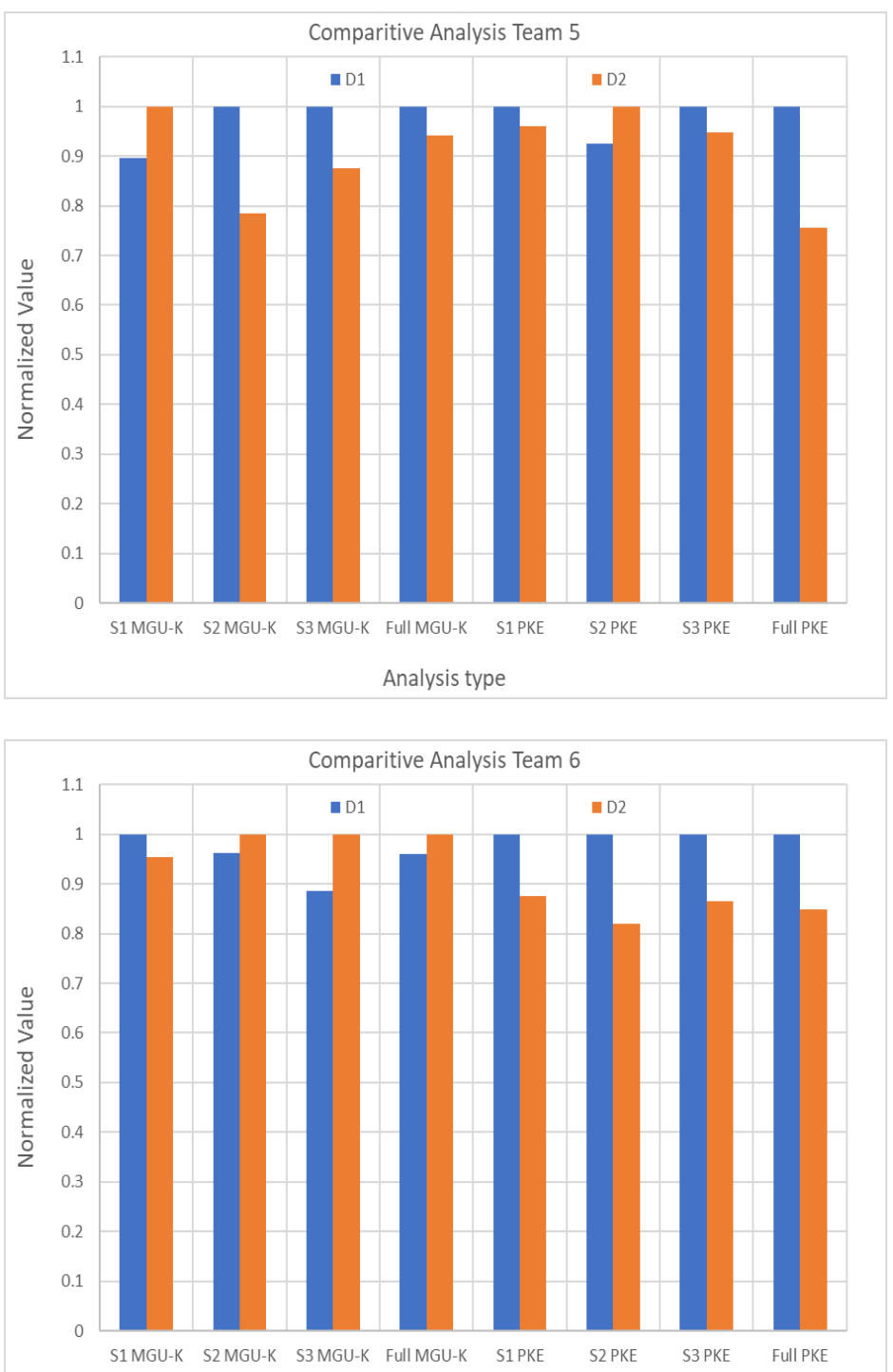

Analysis type

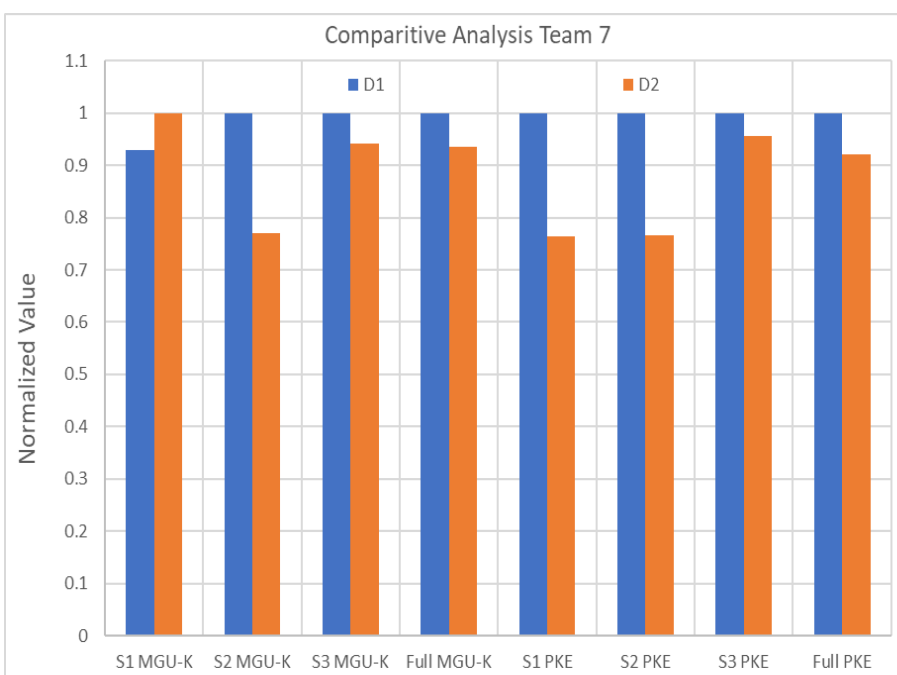

Analysis type
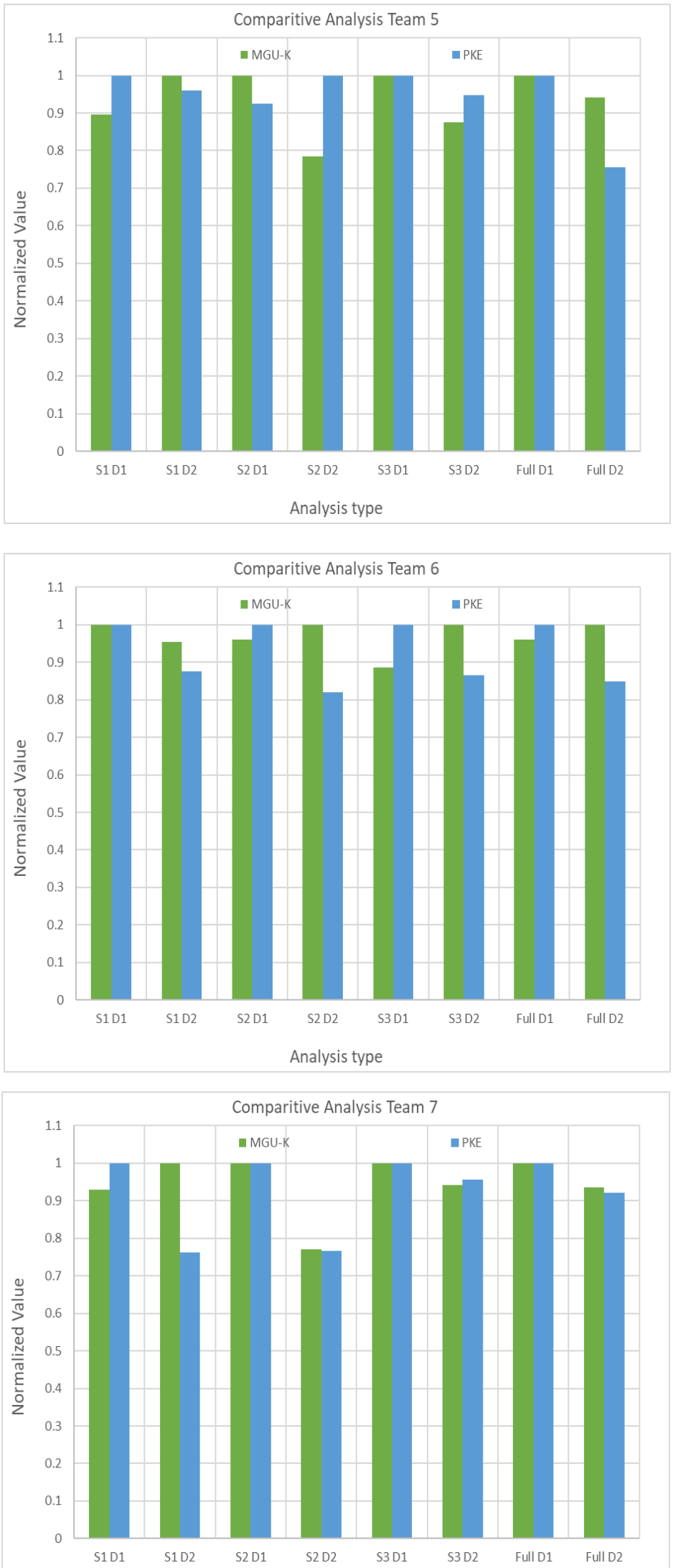

Analysis type 

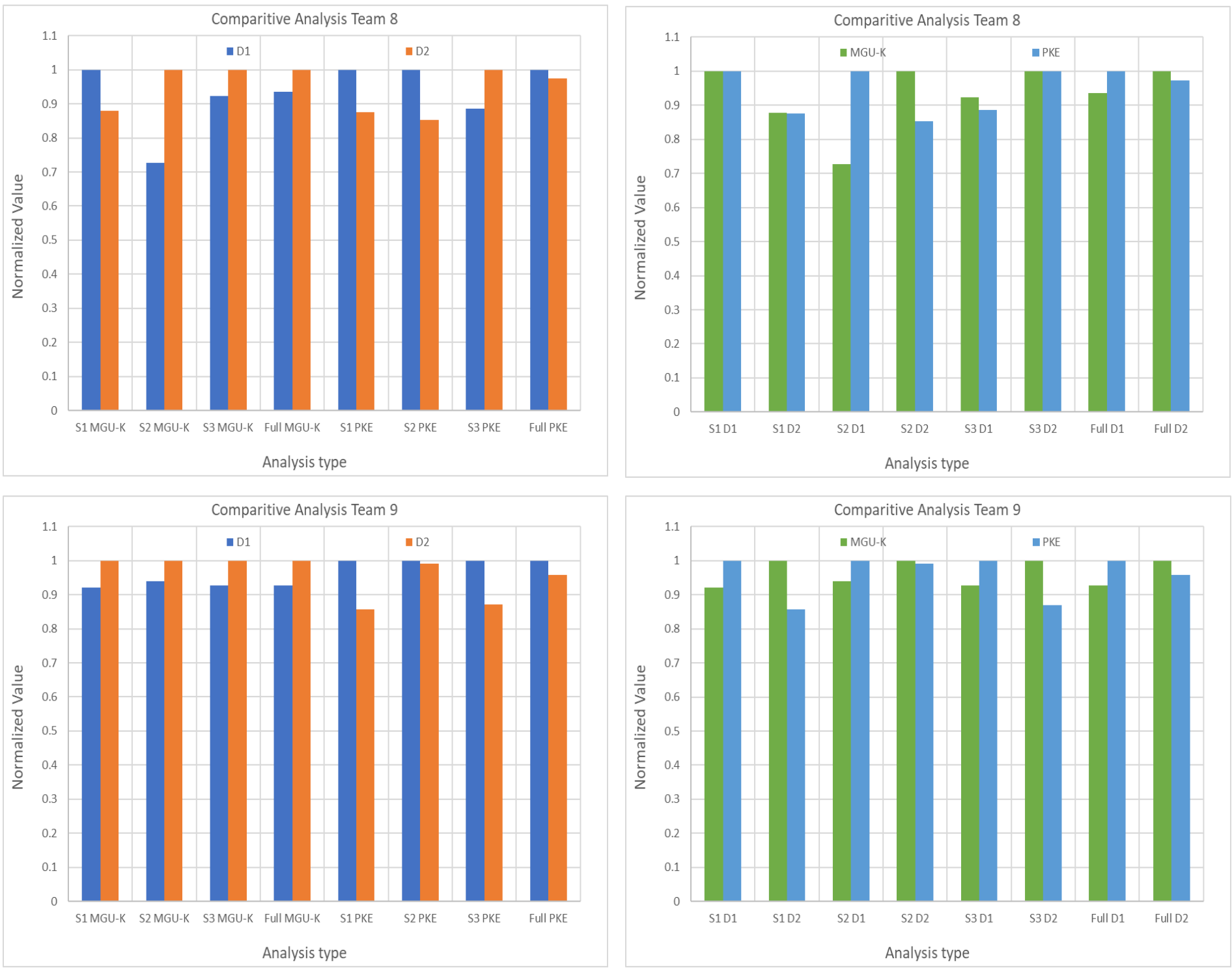

Page 13 of 14 
Appendix II
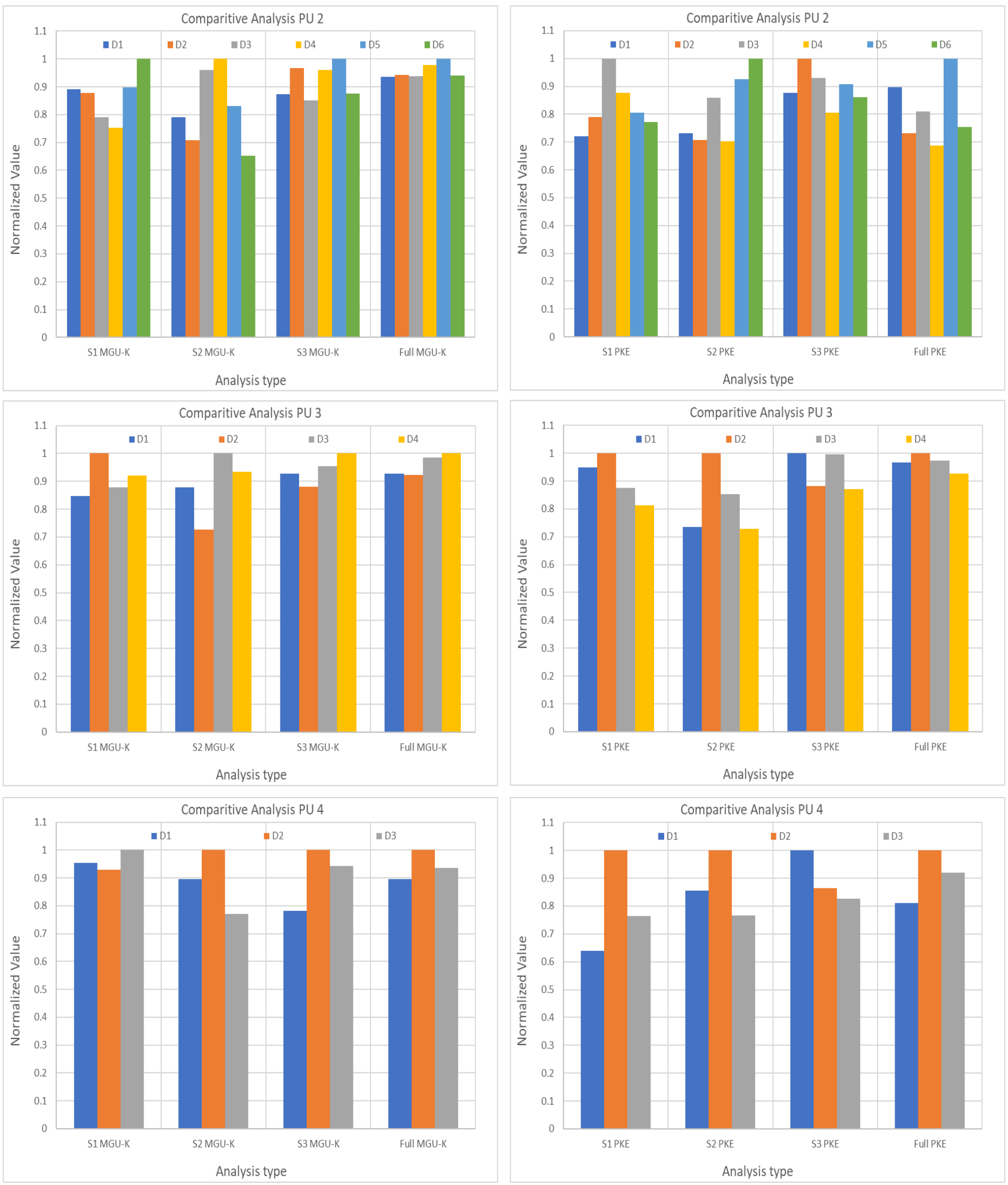

Page 14 of 14 